\title{
Laparoscopic Greater Curvature Plication versus Laparoscopic Sleeve Gastrectomy, a Long- Term Prospective Randomized Comparison
}

\author{
Hamdy Abdelhady,1 ${ }^{1}$ D; Ibrahim H Othman,1 $M D$; Taha A Esmail, ${ }^{1} M D$; \\ Medhat A Ghazy, ${ }^{2}$ MD.
}

1) General Surgery, Tanta University, Egypt.

2) Internal Medicine, Tanta University, Egypt.

Objective: The objective of this prospective randomized study was to compare outcome and complications between LGCP and LSG.

Patients and methods: This study was performed on 40 patients randomly categorized into 2 groups through a computer randomization program. Group $P$ included 20 patients who underwent LGCP. This group was compared to 20 patients who underwent LSG. (Group S). The mean length of follow up was $65.1 \pm 15.7$ and 63.9 \pm 15.6 months $(P=0.810)$.

Results: Mean operative time was $117 \pm 17.9$ in group $P$ and $111 \pm 17.3$ minutes in group $S$ $(P=0.31)$. Mean hospitalization time was $4.85 \pm 1.81$ and $3.55 \pm 1.32$ days $(p=0.013)$. Mean time for return to normal activity was $19.2 \pm 3.69$ and $18.9 \pm 4.29$ days $(p=0.0 .81)$. There was no surgery related mortality. One at each group (5\%) needed conversion to open surgery. Eleven patients (55.0\%) in Group P and 5 patients (25.0\%) in the Group S had minor complications (p 0.02). One patient (5 \%) in Group P had port-site bleeding. In Group S gastric leak occurred in 1 patient. She was treated by re-stapling the leak site and placing an abdominal drain. One patient in the group $S$ required readmission during the first 30 days after surgery, for subphrenic abscess that was treated conservatively. (p: 0.41). During late follow-up, there were 3 surgical interventions, laparoscopic cholecystectomy was done for cholelithiasis in one patient from each group and hernioplasty for umbilical port hernia was done to the other Group $P$ patient. Loss of feeling of hunger at 6, 12 and 60 months postoperatively showed significant differences. The patients in Group S had a greater BMI loss and PEWL after surgery compared with those in Group P. No weight loss failure was observed in any patient of the two groups. After 12 months follow-up, the major comorbidities improved markedly in both groups, and there was no significant difference between the two groups. The mean patient satisfaction score for was $8.75 \pm 1.35$ versus $9.04 \pm 1(p=0.51)$.

Conclusion: LGCP is feasible and safe when applied to morbidly obese patients, but compared with LSG it is inferior to LSG as a restrictive procedure for weight loss, despite its less cost and simpler procedure.

Abbreviations: Body mass index: BMI; laparoscopic adjustable gastric banding: LAGB; laparoscopic greater curvature plication: LGCP; laparoscopic sleeve gastrectomy: LSG; obstructive sleep apnea syndrome: OSAS; percentage of excess weight loss: PEWL.

\section{Introduction:}

Obesity is a major health problem. It is associated with significant comorbid conditions and reduced life expectancy. Since 1997 , obesity has been recognized by the World Health Organization as a global epidemic. In 2014, more than 1.9 billion adults, 18 years and older, were overweight. Of these over 600 million were obese. ${ }^{1,2}$

According to an analysis of trend data 
from 188 countries, more than $58 \%$ of men and $65 \%$ of women across the Middle East and North Africa were found to be either overweight or obese in 2013. Overall, there are an estimated 259 million overweight (180 million) or obese (79 million) people living in the region today. ${ }^{3}$

The prevalence of overweight and obesity in adults in North Africa and the Middle East rose from nearly $53 \%$ to $62 \%$ over 33 -year study period. Several countries in the Middle East showed the largest increase in obesity rates globally, including Bahrain, Egypt, Saudi Arabia, Oman, and Kuwait. ${ }^{4}$

The advent of laparoscopy and the increased awareness of surgery as the only efficient long-term treatment for morbid obesity and its comorbidities have been followed by an enormous increase in the demand for bariatric surgery.

Surgical treatment for obesity is either mal-absorptive, restrictive, or a combination of the two. LSG is the most popular restrictive procedures for morbid obesity. ${ }^{5}$ LGCP is a restrictive technique that reduces the gastric volume by plication of the greater curvature. The mechanism of LGCP is similar to that of LSG in that both result in gastric tube formation and elimination of the greater curvature, but LGCP has the advantage of a reversible restrictive technique without the use of gastrectomy. However, the long-term efficacy is under investigation, and there are very few studies that compare it with other bariatric procedures especially LSG.

The objective of this prospective randomized study was to compare outcomes and complications between LGCP and LSG.

\section{Patients and methods:}

This study was performed in the general Surgery Department, Tanta University Hospitals, Egypt during the period from May 2009 to July 2015 on 40 patients. Full explanation of procedures; possible complications and patient consent were assured before inclusion in the research. The study protocol was approved by the Ethics Committees Tanta University Hospitals.

Patients were randomly categorized into
2 groups through a computer randomization program .

Group P included 20 patients who underwent LGCP. This group was compared to 20 patients who underwent LSG. (Group S).

The inclusion criteria were as follows: BMI over 35 or $30-35 \mathrm{~kg} / \mathrm{m} 2$ accompanied by comorbidities; failure of non-operative treatment after 1 year trial; age 18-50 years; and regular physical activity. Patients who met the inclusion criteria were invited to attend preoperative seminars conducted by our surgeons. All patients underwent a multidisciplinary evaluation performed by internists, psychiatrists and surgeons. Blood tests, abdominal ultrasonography and upper endoscopy were performed preoperatively to establish a baseline.

All the patients were followed up at 1, 3, 6 and then every 6 months. The mean length of follow up was $65.1 \pm 15.7$ months in Group P patients and 63.9 \pm 15.6 months in Group S patients $(\mathrm{P}=0.8097)$. Data on the operative time, hospital stay, overall cost, postoperative complications, feeling of hunger, BMI loss, PEWL and change in comorbidities were analyzed. Loss of appetite and feelings of fullness were evaluated with a questionnaire regarding changes they experienced during the follow-up periods.

Surgical technique: The patient was positioned in a 15-30 degrees reverse Trendelenburg position with both arms placed in abduction and the lower extremities kept straight. Elastic and intermittent pneumatic compressing stockings were applied. The surgeon and camera man stood on the right of the patient, and the assistant stood on the left. Closed pneumoperitoneum of 12-14 $\mathrm{mm} \mathrm{Hg}$ was achieved using a Veress needle. Trocar placement was as follows: one $10 \mathrm{~mm}$ trocar above the umbilicus for the 30 degrees laparoscope; another $10 \mathrm{~mm}$ trocar was placed on the anterior line at the midpoint of the xiphoid and umbilicus for passing the needle, suturing and the surgeon's right hand; one $5 \mathrm{~mm}$ trocar below the xiphoid appendices for liver retraction. A $5 \mathrm{~mm}$ trocar was placed on the right anterior axillary line, 
2-3 cm subcostally for the surgeon's left hand, and another $5 \mathrm{~mm}$ trocar was placed on the left midclavicular line $2-3 \mathrm{~cm}$ subcostally for the surgeon's assistant. Using an ultrasonic scalpel, the omentum and gastroepiploic vessels were dissected from the greater curvature, usually starting at $4 \mathrm{~cm}$ from the pylorus and continuing up to the left crus of the diaphragm and the angle of His. The short gastric vessels, posterior gastric vein and posterior gastric attachments were carefully divided. The anesthesiologist passed down a nasogastric tube of $32 \mathrm{~F}$ directing toward the pylorus. Under its guidance, a row of $8-10$ extramucosal interrupted stitches of 2-0 Ethibond sutures was placed just below the angle of His and continued distally to $4 \mathrm{~cm}$ of the pylorus. The second row of extramucosal running suture lines of 2-0 Prolene was used as reinforcement to narrow the stomach.

Trocar placement and dissection of the gastric greater curvature in Group $\mathrm{S}$ were similar to those in Group P. After a 32F gastric tube was passed down, the stomach was resected from the proximal antrum to the angle of His using linear cutting staplers that was parallel to the gastric tube, along the lesser curvature. The stapler line was reinforced with figure 8 sutures at the junction of two bites or when the excision line was still bleeding. A leak test was done with methylene blue.

Postoperative care: In Group P antispasmodics and proton pump inhibitors were administered intravenously during the postoperative period. Discharge was scheduled provided the patients were able to eat a liquid diet without vomiting. They were advised to eat soft foods 15 days after surgery and solid foods 30 days after surgery. A daily single-dose proton pump inhibitor was prescribed regularly for 30 days.

In Group S, the nasogastric tube was kept in place until gastrointestinal radiography was done to exclude leakage from staple line 1 day after the procedure. The patients were then allowed to drink fluids and discharge was scheduled when an oral intake of 2,000 $\mathrm{ml} / 24 \mathrm{~h}$ was established. The patients were allowed to resume their normal diet gradually in 2 weeks according to patient compliance.

Statistical analysis: Quantitative variables were expressed as mean \pm SD. Qualitative variables were expressed as frequency and percent. Quantitative parametric variables were compared between the two groups using the unpaired student t-test, quantitative nonparametric variables were compared using Mann-Whitney test. Qualitative variables were compared using Chi-square test or Fisher exact test when the criteria for using Chi-square were not sufficient. The power used was 0.80 while the level of significance was $5 \%$.

\section{Results:}

Patients characteristics: The characteristics of the two groups are shown in Table (1). No significant differences were identified with respect to age, gender, baseline BMI or major preoperative comorbidities.

Operative time: In Group P, operative time ranged from 90-150 minutes (mean operative time: $117 \pm 17.9$ minutes). In Group $\mathrm{S}$, operative time ranged from 85-150 minutes (mean operative time: $111 \pm 17.3$ minutes). The difference between the two groups was statistically insignificant $(\mathrm{P}=0.31)$.

Hospitalization time: Hospitalization time ranged from 3-9 days in Group P (mean hospitalization time: $4.85 \pm 1.81$ days). In Group S, hospitalization time ranged from 2-7 days (mean hospitalization time: $3.55 \pm 1.32$ days). The difference between the two groups was statistically significant $(\mathrm{p}=0.013)$.

Time to return to normal activity: Time to return to normal activity ranged from 1324 days in Group P (mean time: 19.2 \pm 3.69 days). In Group $S$, time to return to normal activity ranged from 13-27 days (mean time: $18.9 \pm 4.29$ days). The difference between the two groups was statistically insignificant $(\mathrm{p}=0.0 .81)$.

Early Surgical outcome: There was no surgery-related mortality. All procedures were done laparoscopically except 2 (5\%) conversions to open surgery, one in each group.

According to Clavien classification, ${ }^{6}$ a total of 16 patients with minor complications 
(I-II) were identified, 11 patients $(55.0 \%)$ in Group P and 5 patients (25.0\%) in the Group S (p 0.02). Three patients (7.5 \%) developed major complications (IIIb, and IV), 1 patient (5.0 \%) in Group P, and 2 patients (10.0\%) in Group S.

One patient (5.0\%) in Group P and one patient $(5.0 \%)$ in Group $S$ required reoperation (p: 1). In Group P, there was portsite bleeding in 1 patient and in Group $\mathrm{S}$ gastric leak occurred in 1 patient. She was treated by re-stapling the leak site and placing an abdominal drain. One patient in Group S required readmission during the first 30 days after surgery, for sub-phrenic abscess that was treated conservatively. The difference between the complication rates in two groups was statistically insignificant (p: 0.41). Early minor complications are detailed in Table (2).

Late surgical outcome: During follow-up, there were 3 surgical interventions, 2 patients in group p (10.0\%) and 1 patient (5.0\%) in group s (p: 1). Laparoscopic cholecystectomy was done for cholelithiasis for one patient from each group and hernioplasty for umbilical port hernia was done in group $\mathrm{p}$ patient.

Loss of huger feeling: Loss of feeling of hunger at 6,12 and 60 months postoperatively showed significant differences Table (3).

Analysis of weight loss results: The BMIL and PEWL in the two groups are listed in Tables 4 and 5. No weight loss failure was observed in any patient of the two groups. The patients in Group S had a greater percentage of excess weight loss after surgery compared with those in Group P.

Comorbidities: After 12 months follow-up, the major comorbidities improved markedly in both groups, and there was no significant difference between the two groups Table (6).

Patient satisfaction: Patients were asked to express their satisfaction in a numerical score from 0 to 10 one year after surgery. The mean patient satisfaction score for Group $\mathrm{P}$ patients was $8.750 \pm 1.35$ versus $9.04 \pm 1.43$ for Group $S$ patients. The difference between the two groups was proved to be statistically insignificant $(p=0.51)$.

\section{Discussion:}

Laparoscopic sleeve gastrectomy is part of the definitive bariatric treatment known as duodenal switch. Regan et al. ${ }^{7}$ proposed a two-stage approach in which sleeve gastrectomy was performed first in high-risk patients. This improvement not only reduced surgical morbidity and mortality, but also achieved satisfactory weight loss after the first stage, and it therefore gradually became an independent bariatric procedure. Himpens et al. $^{8}$ reported the long-term outcome of LSG, stating that the mean excess weight loss exceeded $50 \%$ after 6 or more years. Silecchia et al. ${ }^{9}$ reported that although the comorbidities including type 2 diabetes, hypertension and OSAS improved in more than $65 \%$ of cases, complications such as gastric bleeding, leakage and fistula formation also occurred. Although no leakage or gastric bleeding occurred in Group S of our series, the risk of gastrectomy and the long stapler line should not be ignored. A review of the literature showed that the percentage of leakage and hemorrhage in LSG is about 1.2 and $3.6 \%$, respectively, ${ }^{10}$ both difficult to treat, which may prolong the hospital stay. ${ }^{11,12}$

For these reasons, the technique of LGCP was subsequently introduced. The mechanism of LGCP is similar to that of LSG but without partial gastric resection. LGCP can greatly reduce the possibility of leakage and gastric hemorrhage. Ramos et al. ${ }^{13}$ reported a series of LGCP in 42 patients who achieved encouraging weight loss without major complications. The mean PEWL was about $20 \%$ at 1 month, $48 \%$ at 6 months, $60 \%$ at 12 months and $62 \%$ at 18 months. The minor complications such as nausea, vomiting and sialorrhea occurred in 20, 16 and $35 \%$ of their patients, respectively. Skrekas et al. ${ }^{14}$ reported the early-stage outcome of a series of 135 patients, showing that after a mean follow-up of 22.59 months, the mean PEWL was 65.29; the overall complication rate was $8.8 \%$ (12 of 135); and micro-leakage from the suture line, gastric bleeding and obstruction occurred in two, and three patients, respectively. Gastrointestinal bleeding 

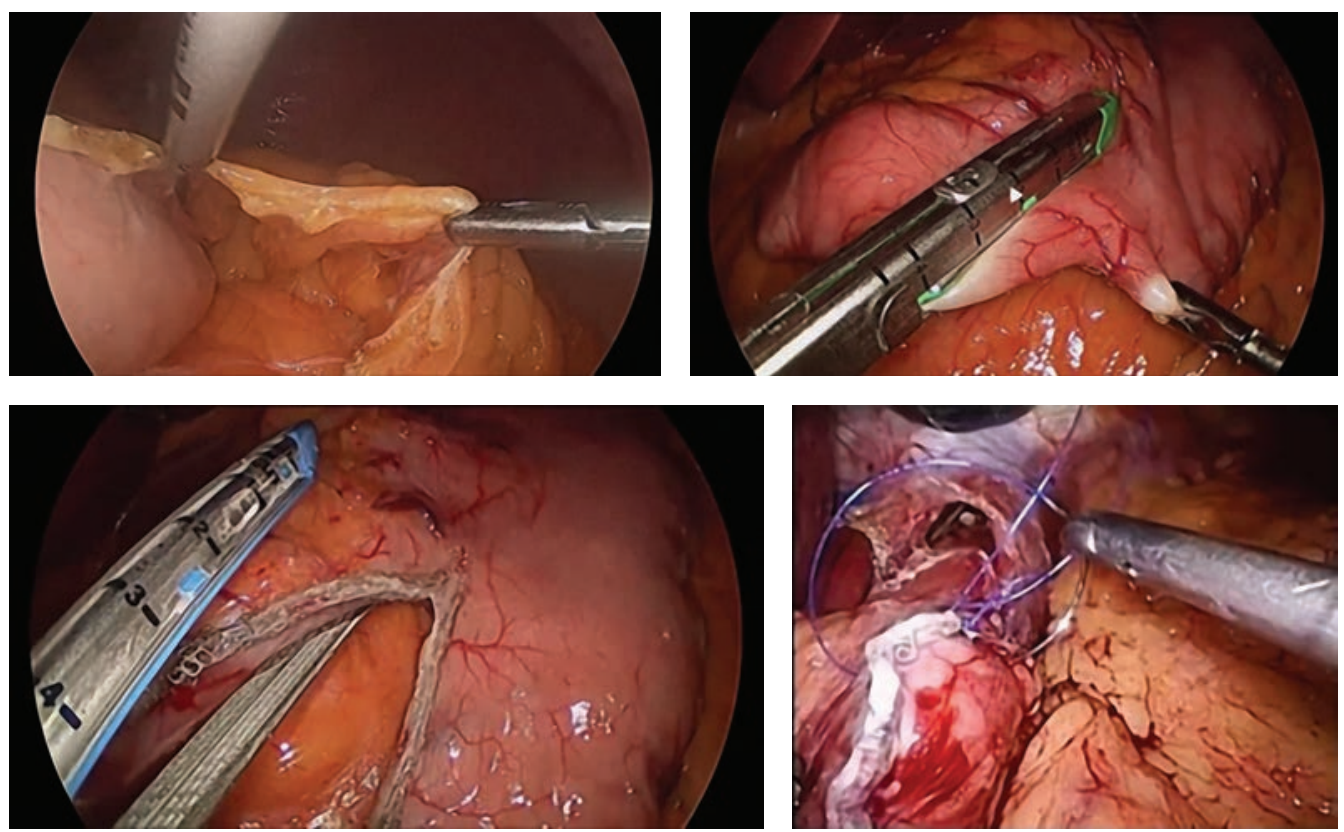

Figure (1): Laparoscopic sleeve gastrectomy.
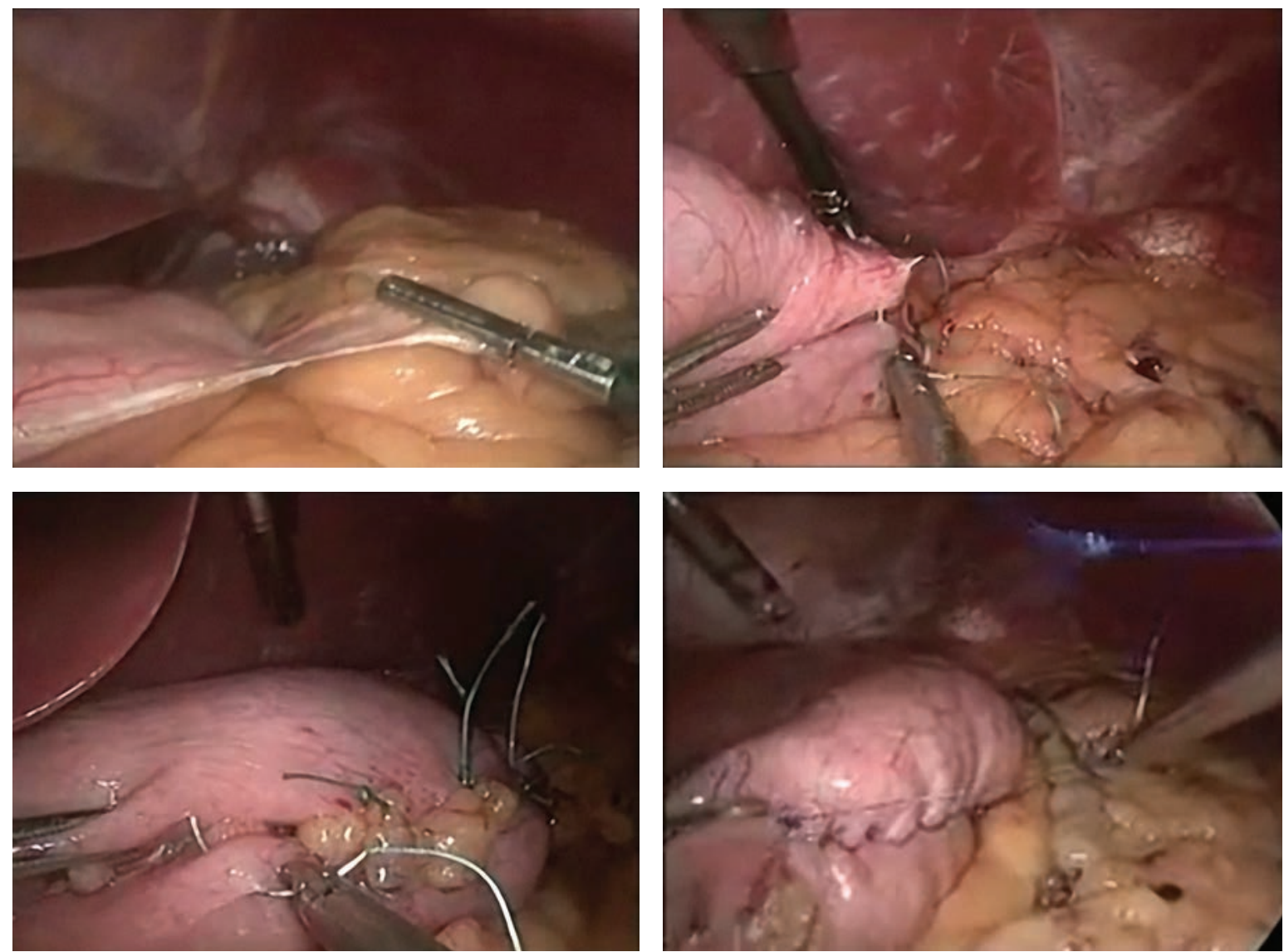

Figure (2): Laparoscopic greater curvature plication.

and leakage in these patients were treated conservatively, and the three cases of acute gastric obstruction were treated surgically. Fried et al. ${ }^{15}$ also reported three major complications in 244 patients of the largest sample clinical study on LGCP, suggesting that the LGCP cannot eliminate the risk of leakage and gastric hemorrhage. Brethauer et al. ${ }^{16}$ analyzed the possible mechanism of postoperative gastric perforation including acute distension of the stomach or severe vomiting with a resultant full-thickness tear 
Table (1): The demographic characteristics and preoperative comorbidities of patients.

\begin{tabular}{|l|l|l|l|}
\hline \multicolumn{1}{|c|}{ Characteristic } & \multicolumn{1}{c|}{$\begin{array}{c}\text { Group P } \\
\text { n (\%) }\end{array}$} & \multicolumn{1}{c|}{$\begin{array}{c}\text { Group S } \\
\text { n (\%) }\end{array}$} & \multicolumn{1}{c|}{ P } \\
\hline Age, (years ) & $42.8 \pm 3.5$ & $44.6 \pm 3.9$ & 0.13 \\
\hline Male / Female & $6(30) / 14(70)$ & $4(20) 16(80)$ & 0.77 \\
\hline BMI (kg/m2 ) & $38.9 \pm 7.3$ & $40.1 \pm 8.2$ & 0.63 \\
\hline Comorbidity: & & & \\
\hline Cardiovascular & $5(25)$ & $4(20)$ & 0.77 \\
\hline Diabetes & $3(15)$ & $3(15)$ & 1 \\
\hline Sleep apnea & $1(5)$ & $1(5)$ & 1 \\
\hline Hyperlipidemia & $2(10)$ & $2(10)$ & 1 \\
\hline Asthma & $1(5)$ & $1(5)$ & 1 \\
\hline Low back pain & $5(25)$ & $6(30)$ & 1 \\
\hline
\end{tabular}

Table (2): Early postoperative complications.

\begin{tabular}{|l|l|l|l|}
\hline \multicolumn{1}{|c|}{ Complication } & \multicolumn{1}{|c|}{$\begin{array}{c}\text { Group P } \\
\mathbf{n ~ ( \% )}\end{array}$} & \multicolumn{1}{c|}{$\begin{array}{c}\text { Group S } \\
\mathbf{n}(\mathbf{\%})\end{array}$} & $\mathbf{P}$ \\
\hline Nausea & $3(15.0)$ & $2(10.0)$ & 1 \\
\hline Vomiting & $2(10.0)$ & $1(5.0)$ & 1 \\
\hline Sialorrhea & $5(25.0)$ & $1(5.0)$ & 0.02 \\
\hline Abdominal pain & $1(5.0)$ & $1(5.0)$ & 1 \\
\hline Total & $11(55.0)$ & $5(25.0)$ & 0.02 \\
\hline
\end{tabular}

Table (3): Postoperative loss of feeling of hunger.

\begin{tabular}{|l|l|l|l|}
\hline Loss of feeling of hunger & \multicolumn{1}{|c|}{ Group P } & \multicolumn{1}{|c|}{ Group S } & \multicolumn{1}{|c|}{ p } \\
\hline 1 month (\%) & $17(85.0 \%)$ & $19(95.0 \%)$ & 1 \\
\hline 6 months (\%) & $10(50.0 \%)$ & $17(85.0 \%)$ & 0.033 \\
\hline 12 months (\%) & $4(20.0 \%)$ & $9(45.0 \%)$ & 0.034 \\
\hline 60 months (\%) & 0 & $4(20.0 \%)$ & 0.011 \\
\hline
\end{tabular}

Table (4): Difference in BMI between groups.

\begin{tabular}{|l|l|l|l|}
\hline & \multicolumn{1}{|c|}{ Group P } & \multicolumn{1}{c|}{ Group S } & \multicolumn{1}{c|}{ p } \\
\hline Baseline & $38.9 \pm 7.3$ & $40.1 \pm 8.2$ & 0.63 \\
\hline 3 months & $33.5 \pm 6.5$ & $33.6 \pm 6.3$ & 0.59 \\
\hline 6 months & $30.0 \pm 8.4$ & $29.7 \pm 6.5$ & 0.9001 \\
\hline 12 months & $26.4 \pm 5.4$ & $24.4 \pm 4.5$ & 0.2109 \\
\hline 24 months & $26.7 \pm 6.2$ & $24.5 \pm 6.5$ & 0.2803 \\
\hline 36 months & $27.4 \pm 7.4$ & $25.3 \pm 5.6$ & 0.3179 \\
\hline 48 months & $27.8 \pm 5.7$ & $25.1 \pm 4.7$ & 0.1104 \\
\hline 60 months & $28.5 \pm 7.5$ & $26.3 \pm 8.4$ & 0.3878 \\
\hline
\end{tabular}


Table (5) :Difference in PEWL between groups.

\begin{tabular}{|l|l|l|l|}
\hline & \multicolumn{1}{|c|}{ Group P } & \multicolumn{1}{c|}{ Group S } & \multicolumn{1}{c|}{ p } \\
\hline 3 months & $28.5 \pm 4.6$ & $29.2 \pm 6.8$ & 0.7051 \\
\hline 6 months & $47.1 \pm 5.4$ & $65.8 \pm 5.6$ & 0.0001 \\
\hline 12 months & $66.1 \pm 3.6$ & $73.2 \pm 6.3$ & 0.0001 \\
\hline 24 months & $64.5 \pm 8.3$ & $71.7 \pm 6.2$ & 0.0001 \\
\hline 36 months & $60.8 \pm 6.7$ & $68.7 \pm 5.6$ & 0.0002 \\
\hline 48 months & $58.7 \pm 4.8$ & $68.5 \pm 6.2$ & 0.0001 \\
\hline 60 months & $55.0 \pm 7.2$ & $64.7 \pm 5.1$ & 0.0001 \\
\hline
\end{tabular}

Table (6): Comorbidity outcomes after at least 6 months.

\begin{tabular}{|c|c|c|c|}
\hline Comorbidity & $\begin{array}{c}\text { Group P } \\
\text { n (\%) } \\
\end{array}$ & $\begin{array}{c}\text { Group S } \\
\text { n (\%) }\end{array}$ & $\mathbf{P}$ \\
\hline $\begin{array}{l}\text { Cardiovascular } \\
\text { Remission } \\
\text { Improvement }\end{array}$ & $\begin{array}{l}4(80) \\
1(20)\end{array}$ & $\begin{array}{l}3(75.0) \\
1(25.0)\end{array}$ & NS \\
\hline $\begin{array}{l}\text { Diabetes } \\
\text { Remission } \\
\text { Improvement }\end{array}$ & $\begin{array}{l}2(66.7) \\
1(33.3)\end{array}$ & $\begin{array}{l}2(66.7) \\
1(33.3)\end{array}$ & NS \\
\hline $\begin{array}{l}\text { Sleep apnea } \\
\text { Remission } \\
\text { Improvement }\end{array}$ & $1(100.0)$ & $1(100.0)$ & NS \\
\hline $\begin{array}{l}\text { Hyperlipidemia } \\
\text { Remission } \\
\text { Improvement }\end{array}$ & $\begin{array}{l}1(50.0) \\
1(50.0)\end{array}$ & $2(100.0)$ & \\
\hline $\begin{array}{l}\text { Asthma } \\
\text { Remission } \\
\text { Improvement }\end{array}$ & $1(100.0)$ & $1(100.0)$ & \\
\hline $\begin{array}{l}\text { Low back pain } \\
\text { Remission } \\
\text { Improvement }\end{array}$ & $\begin{array}{l}4(80.0) \\
1(20.0)\end{array}$ & $\begin{array}{l}4(66.7) \\
2(33.3)\end{array}$ & \\
\hline $\begin{array}{l}\text { Total } \\
\text { Remission } \\
\text { Improvement }\end{array}$ & $\begin{array}{l}12(66.7) \\
5(33.3)\end{array}$ & $\begin{array}{l}12(62.5) \\
6(37.5)\end{array}$ & NS \\
\hline
\end{tabular}

at the suture line and delayed thermal injury of the stomach that occurred during division of the short gastric vessels, particularly if the attachments to the upper pole of the spleen were very short.

The results of our work show that the most common complications in LGCP were nausea, vomiting and sialorrhea, and the incidence of these complications in Group $\mathrm{P}$ was higher than in Group S, probably due to mucosal edema resulting from venous stasis.
Skrekas et al. ${ }^{14}$ modified the LGCP technique by creating a double or triple plication of the opposed gastric wall with the first row of stitches, which greatly improved nausea and vomiting. We did not use this new technique. Instead, we used antispasmodics and proton pump inhibitors with preventive placement of a gastric tube, and the outcome was satisfactory. Our study showed that although the occurrence of such early complications as nausea, vomiting and sialorrhea in Group 
$\mathrm{P}$ was higher than that in the Group S, they were relatively easy to manage, and no such severe complications as hemorrhage, leakage and fistula formation occurred in Group P. The safety of LGCP is comparable to LAGB, which is considered to have the lowest incidence of severe complications of all bariatric procedures. ${ }^{17}$

Our follow-up data revealed that the difference in PEWL was significant between the two groups 6 months after the operation. The difference of BMI loss and PEWL as well as the loss of feeling hunger between the two procedures may be related to two reasons. First, ghrelin may play an important role. Ghrelin is a 28 amino acid peptide and hormone that is produced mainly by enteroendocrine cells in the gastric fundus, ${ }^{18}$ whereas little ghrelin is secreted from the duodenum, ileum and colon. ${ }^{19}$ It is the only known orexigenic hormone whose circulating level increases before meals and decreases with feeding, achieving concentrations sufficient to stimulate hunger and food intake. ${ }^{20,21}$ Langer et al. ${ }^{22}$ reported a prospective study comparing plasma ghrelin levels and weight loss after LSG and LAGB, and found that plasma ghrelin decreased significantly at day 1 after surgery, and remained low and stable at 1 and 6 months after surgery in LSG. In contrast, no change in plasma ghrelin was observed at day 1 after surgery in LAGB patients. In addition, plasma ghrelin levels increased at 1 and 6 months after surgery in LAGB patients, compared with the preoperative levels of the same group. Because it is not necessary to resect the gastric fundus in LGCP, plasma ghrelin levels may not decrease as sharply as the case with LSG, or even increased after surgery.

The other mechanism that can explain the different rate of weight loss may be related to gastric receptive relaxation. The stomach muscle relaxes during eating, and the capacity of the stomach enlarges to keep the internal pressure of the stomach stable. After surgery, the gastric volume may be similar in both procedures, but more stomach wall is preserved in LGCP, resulting in a greater volume of the stomach after relaxation of the stomach muscle. We did not see this mechanism clearly in our series because we could not precisely calculate the volume of stomach after surgery between the two groups. Skrekas et al. ${ }^{14}$ found that in patients with inadequate weight loss, the gastric capacity was noticeably increased 6 months after LGCP by endoscopy, which may support this mechanism.

Gastroesophageal reflux was not observed in our patients. This goes with the results of Brethauer et al., ${ }^{16}$ who reported that no new-onset or worsening of gastroesophageal reflux in their patients during the follow-up periods. They attributed this phenomenon to the mobilization of the gastric fundus and starting LGCP 1 or $2 \mathrm{~cm}$ below the angle of His, so that this fold could potentially serve as an antireflux mechanism.

The improvement of comorbidity was remarkable in both groups. The cause of this improvement may be multifactorial, such as hormonal alterations, ${ }^{23,24}$ BMI loss and decrease in carbohydrate absorption ${ }^{25}$ after bariatric surgery. Randomized researches 26,27 demonstrated that bariatric surgery including gastric bypass LSG and biliopancreatic diversion resulted in better glucose control than did medical therapy in severely obese patients with type 2 diabetes.

We were unable to identify the published literature on the economic evaluation of LGCP versus the other bariatric operations. Given the important technique variation of bariatric surgery and the varying use of devices that greatly influence cost, we reviewed the total cost for LSG and LGCP for the 5 patents in Group P and 7 patients in Group S that were treated in the Economic Paid Hospital to compare the economic costs between these two procedures. LGCP is more advantageous over LSG in terms of cost, and therefore it is more acceptable by patients, especially in developing countries.

\section{Conclusion:}

LGCP is feasible and safe when applied to morbidly obese patients, but compared with LSG it is inferior to LSG as a restrictive procedure for weight loss, despite its less cost 
and simpler procedure.

\section{Reference:}

1- Adeboye B, Bermano G, Rolland C: Obesity and its health impact in Africa: A systematic review. Cardiovasc J Afr 2012; 23(9): 512-521.

2- World Health Organization: Obesity and overweight: Fact sheet $N^{\circ} 311$ Updated 2015 http://www.who.int/mediacentre/factsheets/ fs311/en/

3- World Health Organization (2000), Obesity: preventing and managing the global epidemic: Report of a WHO Consultation (WHO Technical Report Series 894). Languages: English (reprinted 2004), French (2003) pp1-252 ISBN: 9241208945

4- Ng M, Fleming T, Robinson M, Thomson B, Graetz N, Margono C, Mullany EC, Biryukov S: Global, regional, and national prevalence of overweight and obesity in children and adults during 1980-2013: A systematic analysis for the Global Burden of Disease Study 2013. Lancet 2014; 30; 384(9945): 766-781.

5- Colquitt JL, Picot J, Loveman E, Clegg AJ: Surgery for obesity. Cochrane Database Syst Rev 2009; (2): CD003641.

6- Dindo D, Demartines N, Clavien PA: Classification of surgical complications: A new proposal with evaluation in a cohort of 6336 patients and results of a survey. Ann Surg 2004; 240: 205-213.

7- Regan JP, InabnetWB, Gagner M, Pomp A: Early experience with two-stage laparoscopic Roux-en-Y gastric bypass as an alternative in the super-super obese patient. Obes Surg 2003; 13: 861-864.

8- Himpens J, Dobbeleir J, Peeters G: Long-term results of laparoscopic sleeve gastrectomy for obesity. Ann Surg 2010; 252: 319 -324.

9- Silecchia G, Boru C, Pecchia A, Rizzello M, Casella G, Leonetti F, Basso N: Effectiveness of laparoscopic sleeve gastrectomy (first stage of biliopancreatic diversion with duodenal switch) on co-morbidities in superobese high-risk patients. Obes Surg 2006; 16: 1138-1144.

10- Shi X, Karmali S, Sharma AM, Birch DW: A review of laparoscopic sleeve gastrectomy for morbid obesity. Obes Surg 2010; 20: 1171-1177.

11- Campos JM, Siqueira LT, Meira MR, Ferraz AA, Ferraz EM, Guimaraes MJ:
Gastrobronchial fistula as a rare complication of gastroplasty for obesity: A report of two cases. J Bras Pneumol 2007; 33: 475-479.

12- Casella G, Soricelli E, Rizzello M, Trentino P, Fiocca F, Fantini A, Salvatori FM, Basso $\mathrm{N}$ : Nonsurgical treatment of staple line leaks after laparoscopic sleeve gastrectomy. Obes Surg 2009; 19: 821-826.

13- Ramos A, Galvao Neto $M$, Galvao $M$, Evangelista LF, Campos JM, Ferraz A: Laparoscopic greater curvature plication: Initial results of an alternative restrictive bariatric procedure. Obes Surg 2010; 20: 913-918.

14- Skrekas G, Antiochos K, Stafyla VK: Laparoscopic gastric greater curvature plication: results and complications in a series of 135 patients. Obes Surg 2011; 21: 1657-1663.

15- Fried M, Dolezalova K, Buchwald JN, McGlennon TW, Sramkova P, Ribaric G: Laparoscopic greater curvature plication (LGCP) for treatment of morbid obesity in a series of 244 patients. Obes Surg 2012; 22: 1298-1307.

16- Brethauer SA, Harris JL, Kroh M, Schauer PR: Laparoscopic gastric plication for treatment of severe obesity. Surg Obes Relat Dis 2011; 7: 15-22.

17- Buchwald H, Avidor Y, Braunwald E, Jensen MD, Pories W, Fahrbach K, Schoelles K: Bariatric surgery: A systematic review and meta-analysis. JAMA 2004 ; 292: 1724-1737.

18- Inui A, Asakawa A, Bowers CY, Mantovani G, Laviano A, Meguid MM, Fujimiya M: Ghrelin, appetite, and gastric motility: The emerging role of the stomach as an endocrine organ. FASEB J 2004; 18: 439-456.

19- Date Y, Kojima M, Hosoda H, Sawaguchi A, Mondal MS, Suganuma T, Matsukura S, Kangawa K, Nakazato M: Ghrelin, a novel growth hormone-releasing acylated peptide, is synthesized in a distinct endocrine cell type in the gastrointestinal tracts of rats and humans. Endocrinology 2000; 141: 4255-4261.

20- Cummings DE: Ghrelin and the short- and long-term regulation of appetite and body weight. Physiol Behav 2006; 89: 71-84.

21- Kirchner H, Heppner KM, Tschop MH: The role of ghrelin in the control of energy balance. Handb Exp Pharmacol 2012; 209: 161-184.

22- Langer FB, Reza Hoda MA, Bohdjalian A, Felberbauer FX, Zacherl J, Wenzl E, 
Schindler K, Luger A, Ludvik B, Prager G: Sleeve gastrectomy and gastric banding: Effects on plasma ghrelin levels. Obes Surg 2005; 15: 1024-1029.

23- Wu J, Ye H, Wang Y, Zhu Y, Xie Z, Zhan $\mathrm{X}$ : Comparative study of laparoscopic sleeve gastrectomy with and without partial enterectomy and omentectomy. Surg Obes Relat Dis 2012; 8: 275-280.

24- Harvey EJ, Arroyo K, Korner J, Inabnet WB: Hormone changes affecting energy homeostasis after metabolic surgery. Mt Sinai J Med 2010; 77: 446-465.

25- Stanhope KL, Schwarz JM, Keim NL, Griffen SC, Bremer AA, Graham JL, Hatcher B, Cox CL, Dyachenko A, Zhang W, McGahan JP, Seibert A, Krauss RM, Chiu S, Schaefer EJ, Ai M, Otokozawa S, Nakajima K, Nakano
T, Beysen C, Hellerstein MK, Berglund L, Havel PJ: Consuming fructose-sweetened, not glucose-sweetened, beverages increases visceral adiposity and lipids and decreases insulin sensitivity in overweight/obese humans. J Clin Invest 2009; 119: 1322-1334.

26- Mingrone G, Panunzi S, De Gaetano A, Guidone C, Iaconelli A, Leccesi L, Nanni G, Pomp A, Castagneto M, Ghirlanda G, Rubino F: Bariatric surgery versus conventional medical therapy for type 2 diabetes. $N$ Engl $J$ Med 2012; 366: 1577-1585.

27- Schauer PR, Kashyap SR, Wolski K, Brethauer SA, Kirwan JP, Pothier CE, Thomas S, Abood B, Nissen SE, Bhatt DL: Bariatric surgery versus intensive medical therapy in obese patients with diabetes. $N$ Engl J Med 2012; 366: 1567-1576. 